\title{
Autoria e humanização em Neide Duarte
}

\author{
Jorge Kanehide Ijuim e Moema Guedes Urquiza
}

\section{Sobre os autores}

Doutor em Ciências da Comunicação/ Jornalismo pela Escola de Comunicação e Artes da USP, professor do Curso de Jornalismo da UFSC e coordenador do projeto de pesquisa "O real e o poético na narrativa jornalistica” - UFSC ijuim@cce.ufsc.br

Graduada em Jornalismo pela UFMS, especialista em Comunicação Social pelo SEPAC/ USF-Bragança Paulista, colaboradora voluntária do projeto de pesquisa "O real e o poético na narrativa jornalistica”, coordenado pelo Prof.

Dr. Jorge Kanehide Ijuim - UFSC moema_urquiza@hotmail.com

\section{Resumo}

No exercício do jornalismo diário, a busca excessiva pela racionalidade leva ao predomínio da desumanização do ser humano. O jornalismo contemporâneo revela um ou alguns aspectos do fato nuclear, destaca-os da realidade e reconstrói essa mesma realidade ignorando a complexidade da sociedade humana. É a coisificação do fato jornalístico - onde originalmente estão incluídos o ser humano e a sua circunstância. A realidade é una, complexa, não fragmentada e merece ser reportada para além do simples relato dos fatos. Leitores/telespectadores-sujeitos têm o direito a uma narrativa jornalística que lhes amplie a compreensão da realidade; que seja desafiadora e, ao mesmo tempo, criativa, estética, responsável. A pessoa Neide Duarte e seu fazer jornalístico são um bom exemplo.

Palauras-chave:

Jornalismo, Humanização da notícia, Literatura, Figuras de linguagem

\section{Authorship and humanizing in Neide Duarte}

\section{Abstract}

In the practice of daily journalism, an extreme search for the rationality leads to the predominance of the dehumanized of the human being. Contemporary journalism discloses one or some aspects of the main story, detaches them from reality and then reconstructs this same reality ignoring the complexity of human society. It is a process of reification of the journalistic fact - where the original human being and their circumstance are no longer included. Reality is whole, complex, not broken up, and deserves to be reported beyond the simple recounting of facts. Readers/viewers as subjects have the right to a journalistic narrative that extends their understanding of reality: that is to say challenger issues while at the same time being creative, aesthetic and responsible. Neide Duarte and her journalism is one example of good practice.

Key words:

Journalism, Humanizing the news, Literature, Figures of speech 
Uma das expressões comuns entre os profissionais da comunicação é o famoso "faro jornalístico". Há certa unanimidade entre os observadores e estudiosos do jornalismo atual de que a perda do "faro" está diretamente ligada às comodidades tecnológicas a que têm acesso os profissionais. Mas há quem diga que a falta de apuração aliada à pouca compreensão da realidade, que é complexa, e à deficiente formação humanística e estética dos profissionais da comunicação também contribuem muito para isso.

Mais do que conhecimento sobre o assunto, o "faro jornalístico" é uma mistura que envolve também experiência acumulada, sensibilidade, capacidade de estabelecer conexões e até um "sexto sentido". Sim, porque, narrar a realidade compreende abrir todos os sentidos para captá-la, sempre na perspectiva de reportá-la com responsabilidade. Não se trata de ligar o gravador, de trocar mensagens eletrônicas ou algumas palavras pelo telefone. Uma vez pautado, o jornalista precisa estar com todos os sentidos abertos à realidade que vai encontrar. Ir ao encontro do outro, não apenas física, mas emocionalmente. Um jornalismo à flor da pele. Isso significa ouvir, ver, tocar, sentir, cheirar mesmo; ampliar as possibilidades de questionamentos, desprovido de qualquer pre-conceito e, ao mesmo tempo, na certeza de que o ser humano jornalista reporta o ser humano fonte. Ou seja: ambos são seres humanos complexos, falíveis, contraditórios, históricos, sujeitos de interesses e visões de mundo diferentes. É preciso estabelecer o diálogo, com vistas a atingir a comunhão. Como afirma Cremilda Medina (2006: 69), "Comunhão, a plenitude da comunicação, ocorre na tríplice tessitura da ética, técnica e estética". E questiona: "como criar uma narrativa ao mesmo tempo sedutora e inusitada, se a estética está aprisionada a regras de uma razão instrumental que, por sua vez, não legitima a emoção como força motriz do ser humano?" (Medina, 2006: 70). Na contramão do excesso de racionalidade, a subjetividade apresenta-se como uma resposta necessária e inevitável para a construção de narrativas densas, criativas e responsáveis. A técnica jornalística, o intelecto, deve caminhar junto com a estética, com a emoção, a intuição, ladeadas pela ética.

Nesse mesmo sentido, Carlos Alberto Vicchiatti (2005: 26) chama a atenção para os perigos do "jornalismo mecânico", que tem função informativa, rápida e mecânica, em que o essencial perde-se, em que o conteúdo fica prejudicado. Além disso, para Vicchiatti (2005: 21),

a estética (no sentido mais amplo) fica de lado e, portanto, não é preocupação fundamental do jornalismo. Noticia-se o fato espetacular, catastrófico, frio. Esquece-se que em todas as situações noticiadas há pessoas envolvidas. Não se pensa que uma notícia calamitosa também pode ser divulgada sem sensacionalismo. Esquece-se do ser humano.
Narrar a realidade compreende abrir todos os sentidos para captá-la, sempre na perspectiva de reportá-la com responsabilidade 
Imbuído da tarefa de mediador social, o jornalista deve construir um texto que leve os leitores a ampliar seu conhecimento da realidade, uma vez provocados, questionados e instigados pelo conteúdo jornalístico. Uma narrativa que seja capaz de fazer a diferença, causar movimento, desestruturar, desconstruir, mexer com a vida das pessoas. Tal procedimento vai muito além do domínio das técnicas, da pauta fria, da captação de informações, da estruturação da matéria para torná-la acessível e universal. Passa por um aprimoramento em todas as dimensões do ser humano, por uma apuração consequente e responsável, e pela convicção de que, como mediador, não cabe ao jornalista dar respostas prontas, nem convencer o leitor com a "verdade" dos fatos. Vicchiatti (2006: 91-92) suscita essa questão: o texto jornalístico é verdadeiro ou verossímil?

\begin{abstract}
O ser humano não expõe, puramente, as coisas - dobra-as, mascaraas, conforme o modo como as vê. Ao trabalhar com o acontecimento presente em um passado imediato, aquilo que o jornalismo apresenta não é a realidade, mas sua representação, com toda a subjetividade que um olhar pode carregar. O jornalismo (...) faz uma reconstrução desse passado, mas sem jamais conseguir recuperar o real em sua totalidade. Seu olhar [do jornalista] sofre essa influência que certamente será transmitida na narrativa. A verossimilhança pode ocupar o lugar da verdade como matéria-prima do texto jornalístico. Compõe o texto a vivência do narrador que o elabora.
\end{abstract}

Ser capaz de estabelecer nexos complexos, traduzir idéias, termos, noções de diversas áreas do conhecimento, promover o confronto/o encontro entre humanos, permitir que outros seres humanos falem já é um bom começo para a prática de um jornalismo autoral. Retomando Vicchiatti (2005: 51):

O jornalista preocupado com a estética e com o social compreenderá que é integrante de uma sociedade, de uma comunidade. Do contrário, poderá sentir-se acima do bem e do mal, isento de qualquer emoção e de qualquer participação no cotidiano de sua comunidade.

O profissional, consciente de sua responsabilidade social, é capaz de criar, ousar, transformar sua pauta em projeto, lançar mão das mais diversas ferramentas para produzir a reportagem, ocupando todos os espaços e possibilidades que o veículo lhe proporciona. Lançar-se ao inesperado, aberto a todas as alternativas que podem, inclusive, desconstruir certezas.

Partindo do entendimento de que os fenômenos sociais são complexos, das múltiplas causas e consequências que envolvem os conflitos do cotidiano, e da inevitável (e necessária) subjetivi-

Estudos em Jornalismo e Mídia - Ano VI - n. 1 pp. 85 - 97 jan./jun. 2009 
dade inerente aos atores sociais - jornalistas inclusive - e suas ações humanas, muito se tem discutido sobre o diálogo entre jornalismo e literatura. Tais reflexões surgem como uma alternativa ao agonizante modelo de jornalismo que é praticado na imprensa diária, pela maioria dos veículos de comunicação.

Tanto o jornalismo como a literatura têm como ferramenta de trabalho a palavra, essa unidade do discurso grávida de significados. E, a partir da palavra, um e outro campo do conhecimento tem diante de si a arte de organizar a realidade em narrativa, tecendo o discurso e apresentando-o com coerência ao leitor/espectador. Endosso Cremilda Medina quando define a narrativa como "uma das respostas humanas diante do caos" (2006: 67):
Muito se tem discutido sobre o diálogo entre jornalismo e literatura. Tais reflexões surgem como uma alternativa ao agonizante modelo de jornalismo que é praticado na imprensa diária

Dotado da capacidade de produzir sentido, ao narrar o mundo, o sapiens organiza o caos em um cosmos. O que se diz da realidade constitui uma outra realidade, a simbólica. Sem essa produção cultural - a narrativa - o humano ser não se expressa, não se afirma perante a desorganização e as inviabilidades da vida. Mais do que o talento de alguns, poder narrar é uma necessidade vital.

O jornalista é chamado a ser mediador-autor de uma comunicação que se quer dialógica, dialética e responsável. "Esse vaso comunicante não é um difusor que conforma o grande público, mas um artesão criativo do diálogo transformador da ciência e do saber cotidiano" (ibidem: 14). O desafio é justamente passar a olhar o exercício do jornalismo com a mesma autoria - originalidade da atividade de um artesão. O artesão colhe a matéria-prima bruta - a madeira, a pedra, o sisal... - e talha, esculpe, trama, com cuidado, peças singulares, de valor único, com contexto, carregadas de significado. É claro que jornalismo exige exatidão, fatos e personagens reais. Ao contrário da literatura. Como bem afirma Nelson Traquina, "o principal produto do jornalismo contemporâneo, a notícia, não é ficção, isto é, os acontecimentos ou personagens das notícias não são invenção dos jornalistas" (2005: 20). O mesmo autor ainda acrescenta: “a transgressão da fronteira entre realidade e ficção é um dos maiores pecados da profissão de jornalista, merece a violenta condenação da comunidade e quase o fim de qualquer promissora carreira de jornalista" (idem, ibidem). Mas, é possível emprestar elementos da literatura para tornar os textos jornalísticos mais leves, atraentes, sedutores, humanos. No dizer de Cremilda Medina (2006: 69): "essa é a marca de autor que se aspira: contar sua história ou a história coletiva de forma sutil e complexa, afetuosamente comunicativa e iluminando no caos alguma esperança do ato emancipatório". Nessa mesma direção, acrescenta Vicchiatti (2005: 85): 
Dos textos frios, apenas tecnicamente corretos, os profissionais de imprensa partem em busca de uma maior identificação com o leitor, recheando informações com histórias de vida, trazendo emoções e sentimentos para revelar o colorido dos fatos cotidianos.

Mantidos os princípios técnicos e éticos da narrativa jornalística, esta ganha vitalidade e beleza quando se aproxima do texto literário. Mais do que isso: é possível tornar o texto mais denso e complexo, sem perder a clareza e a universalidade, sem perder de vista a importância de representar a realidade de maneira mais completa ao leitor, ampliando sua capacidade de compreensão e conhecimento e oferecendo-lhe instrumentos com os quais poderá decidir, tomar partido, opinar, transformar sua vida e sua realidade.

Ao falar das afinidades entre jornalismo e literatura, Alex Galeno considera a literatura como o "fermento para desobstruir a imaginação jornalística”. Afirma que (Galeno, 2002: 107):

Jornalismo e literatura, ao deixarem de ser praticadas como áreas fatiadas do conhecimento, gramáticas herméticas e específicas, convocam escritores e jornalistas a se soltarem dos mastros do dogmatismo e da arrogância, permitindo-se escutar cantos de boas novas e surpreender as infra-estruturas tácitas de conceitos ao dialogarem com o contraditório, o antagônico e o diferente.

Galeno, no mesmo artigo intitulado poeticamente Palavras que tecem e livros que ensinam a dançar, nos lembra que "literatura é comunicação" e nos remete à origem da palavra texto, que vem do latim textus e, "como particípio passado textere indica, em sentido figurado, que o conjunto linguístico de um discurso expressa a metáfora de um tecido (...) Ou ainda, como algo que contém uma textura”. Dessa forma, afirma Galeno,

o texto deverá ser percebido como algo tátil, exuberante e como uma rede comunicativa de múltiplos sentidos. Textos tecidos que, pela mobilidade conectiva de seus escritores se transformam em fantasias e vestimentas para os dançarinos leitores.

A comparação utilizada por Galeno - dançarinos leitores faz-nos lembrar da condição de sujeitos, do protagonismo que é exercido pelos seres humanos que, de uma forma ou de outra, são "atingidos" pela narrativa jornalística. Sujeitos históricos e complexos, os leitores, telespectadores ou ouvintes participam ativamente no processo comunicativo, como co-autores, uma vez que ao texto veiculado acrescenta-se a interpretação desses sujeitos. Cada um lê o texto sob a sua ótica, a seu tempo, com seu
Mantidos os princípios técnicos e éticos da narrativa jornalística, esta ganha vitalidade e beleza quando se aproxima do texto literário 
referencial teórico e histórico. Alberto Dines coloca o leitor como "princípio e fim" do processo comunicativo. Para ele, "o indivíduo é um conjunto, um microcosmo da sociedade que ele compõe e não uma unidade indivisível e estática" (1986: 57). Os leitores querem saber "como vivem, o que pensam, como reagem aqueles que sofrem a ação dos fatos" (Vicchiatti, 2005: 88); (...) "uma informação diferente que lhes permita o entendimento aprofundado do fato político, econômico, científico, esportivo que ele 'viu', na véspera, na televisão" (idem: 108).

\section{Recursos retóricos}

Muito utilizadas na literatura, mas também, com menor frequência, no texto jornalístico, as figuras de linguagem são ferramentas, estratégias de que o autor pode lançar mão para explorar uma palavra ou expressão, comparar, realçar sonoridade, buscando sempre ampliar a compreensão do texto. Não é nossa intenção, neste artigo, aprofundar o aspecto gramatical de cada uma das dezenas de figuras de linguagem disponíveis na Língua Portuguesa. Destacamos, para fins deste estudo, apenas as seguintes figuras: antítese, ironia, metáfora, metonímia e prosopopéia.

A antítese é uma figura de linguagem em que há exposição de idéias opostas. A ironia é um instrumento muito utilizado pela literatura, em que o autor quer dizer exatamente o contrário do que está expondo, "brincando" com alguém ou alguma situação. Com a metáfora, comparam-se dois elementos, sem necessariamente o uso de conectivo comparativo (como), quando uma palavra que designa uma coisa passa a designar outra por haver alguma semelhança entre ambas. Já na metonímia, como na metáfora, uma palavra que tem originalmente um significado passa a ter outro; entretanto, isso não acontece por traços de semelhança entre ambas, mas porque existe um relacionamento direto entre elas. Emprega-se um termo no lugar de outro, substituindo, por exemplo, o efeito pela causa, a marca pelo produto, o autor pela obra, o lugar pela coisa, a parte pelo todo etc. A prosopopéia ou personificação é uma figura que atribui características, sentimentos e ações próprias dos seres humanos ou animação a objetos inanimados ou seres irracionais, transformando-os em personagens.

\section{As narrativas de Neide Duarte}

Durante quase uma década, a jornalista Neide Duarte viajou pelo Brasil garimpando histórias de pessoas, comunidades, ONGs, empresas da iniciativa privada ou do poder público, que desenvolvessem projetos de melhoria das condições de vida de populações empobrecidas. Os documentários jornalísticos foram veiculados no Programa "Caminhos e Parcerias", da TV Cultura/SP. 
Nos últimos anos, as reportagens de Neide Duarte voltaram ao jornalismo diário. E, para acabar com qualquer dúvida e, ao contrário do que acreditam os jornalistas mecanicistas de plantão, é possível produzir um jornalismo autoral, estético, criativo e comprometido com o ser humano para ser veiculado na dita "grande imprensa", como o Jornal Nacional, o Jornal Hoje ou o Bom Dia Brasil da Rede Globo de Televisão. Neide Duarte é um bom exemplo. Há muitos outros sinais de beleza, profundidade, ética e responsabilidade no telejornalismo diário, na imprensa escrita, nos programas de radiojornalismo ou mesmo nos sites noticiosos, reino das notícias "minuto a minuto". São frases e enfoques diferenciados; abordagens literárias; abertura a fontes nunca antes ouvidas; temas que, normalmente, não teriam espaço na grande imprensa; entrevistas que concretizam o "diálogo possível" proposto por Cremilda Medina (1995).

Na contramão do jornalismo mecânico, praticado como mandam os manuais de redação, que não deixa espaço para a criatividade e a autoria e, consequentemente, compromete o entendimento do leitor e seu aprofundamento no assunto, Neide Duarte pratica e compreende o jornalismo como uma possibilidade concreta de transformação da realidade. Para ela, "o jornalista pode mobilizar a ação das pessoas e plantar novos valores, novos comportamentos". E sabe que isso é "poder político".

\begin{abstract}
A responsabilidade do jornalista é perceber isso [uma sociedade menos disposta à reflexão] e cuidar das palavras, das informações que vai trazer para o público, trazendo coisas que convoquem as pessoas para uma nova realidade. Por exemplo, ao dar espaço para que jovens da periferia apareçam na mídia, para mostrar o seu talento e não para dizer como é violenta a periferia das grandes cidades, uma mudança significativa está a caminho. Aquele jovem e todos os outros que assistirem àquela reportagem vão perceber que eles podem estar em evidência pelas qualidades que têm, seja escrevendo, fazendo um jornal, criando uma rádio comunitária, construindo enfim alguma coisa e não pela violência do lugar em que vivem. (Duarte, 2004.)
\end{abstract}

Chamou-nos a atenção o testemunho de que foi ao longo das produções do "Caminhos e Parcerias" que Neide Duarte percebeu um outro País, um outro jeito de fazer jornalismo e a profundidade da responsabilidade social do jornalista. Ou seja: a própria realidade, seu contato com as pessoas simples, com as ações humanas é que foi ampliando sua capacidade de percepção, sua sensibilidade, seu compromisso e ética profissionais. O caminho foi educativo.

O jornalista é um mediador entre dois mundos. E isso não significa apenas poder, mas também humildade, aceitação, de ser apenas o que deixa passar, deixa fluir através de seu trabalho o trabalho de outros, as idéias 
de outros, o caráter de outros. O jornalista não é só um representante que age em nome de tantos outros, é também um intérprete que busca revelar o que acredita ser verdade e o que acredita que as pessoas querem saber. Uma profissão repleta de subjetividades. De objetivo mesmo, uma única certeza, na página do jornal: a data. (Idem, 2004.)

A pessoa Neide Duarte impregnou de humanidade a jornalista Neide Duarte. E vice-versa:

Eu já entrevistei vários jovens infratores da periferia de São Paulo, que falam em sequestros relâmpagos, em mortes, como se fossem nada. Uma menina de 15 anos me contou rindo que estava ali porque tinha feito um sequestro relâmpago e eu senti no olhar e no sorriso dela [grifo nosso], que ela dizia aquilo como quem conta que cabulou uma aula. Ela não tinha idéia da diferença de valores. Ela aprendeu que a vida humana não vale nada. (Idem, 2003.)

É claro que tal realidade não desponta na grande mídia apenas por mérito dos profissionais que, como Neide Duarte, fazem a diferença. Mas, a criatividade, a capacidade de ousar, o domínio da pauta, o refinamento estético, o hábito da leitura, a certeza de que são profissionais a serviço do interesse público e da transformação da realidade e não celebridades a serem cultuadas, são características determinantes nestes jornalistas-mediadores, autores criativos.

\footnotetext{
Mudar essas relações de poder, de prioridade de consumo, passa pelas mãos do jornalista. Ele pode ter uma imensa contribuição na mudança de uma consciência ética de uma população. É o jornalista quem faz circular valores, interesses. É ele quem mantém acesa uma interpretação de mundo, ao ter o poder de ser os olhos dos outros homens, ao ter o poder de ser o coração de outros homens (Idem, 2004.)
}

Neide Duarte ambientaliza, descreve, dá tons e nuances; costuma nos trazer para o texto de sua reportagem como se nós mesmos - espectadores, leitores - estivéssemos ali, vivenciando o que ela reporta. Utiliza, entre outros recursos, as figuras de linguagem, já mencionadas neste texto, para tornar a narrativa mais bela, leve e em algumas situações até poética. Mas esse recurso torna também a realidade reportada mais viva: traz cheiros, cores, subjetividades. São metáforas, prosopopéias, metonímias, pleonasmos, em meio a diálogos literalmente em travessões, descrições, imersão no cenário descrito, histórias de vida. A reportagem torna-se mais humana, densa, complexa, como o é, de fato, o mundo em que vivemos. Sua narrativa leva o sujeito-leitor a pensar, a buscar compreender melhor o que se passa, as razões, os interesses, as variantes do caso relatado. Ao mesmo tempo, é capaz de nos dar prazer, porque ler ou ouvir Neide Duarte torna-se uma aventura envolvente.

\footnotetext{
Estudos em Jornalismo e Mídia - Ano VI - n. 1 pp. 85 - 97 jan./jun. 2009
} 
É o caso da reportagem "Protesto e dor", veiculada no telejornal Bom Dia Brasil da Rede Globo no dia 30 de julho de 2007, depois do trágico acidente com o Airbus da TAM em Congonhas, no dia 17 do mesmo mês. Poderia ser apenas mais uma reportagem repleta de números, informações da Defesa Civil, do Instituto Médico Legal, da TAM ou da Infraero. Poderia ser apenas um balanço do número de mortos, dos corpos encontrados, das vítimas ainda desaparecidas ou dos procedimentos que os passageiros de vôos futuros deveriam tomar para manter a normalidade da vida. Mas a reportagem de Neide Duarte foi muito além de tudo isto e, com ousadia, inverteu a lógica:

O domingo foi de mobilização em São Paulo. Milhares de pessoas foram às ruas homenagear as vítimas da tragédia com o Airbus da TAM. Havia faixas de protesto, palavras de solidariedade e de indignação. A caminhada de cinco quilômetros terminou em frente ao local da tragédia. Entre os presentes, o que se viu foi uma mistura de revolta, dor e solidariedade.

São Paulo ainda tem nuvens escuras no seu céu. Da bandeira do Brasil que tremulava, sobrou só um fiapo. As luzes que resistiram se equilibravam com precariedade. Os aviões continuam a descer num retrato mal acabado de aeroporto.

Nós estamos distantes, pequenos, diminuídos na nossa cidadania. De longe, nem parece que somos nós, ocupando uma parte da avenida. Mas estamos lá, caminhando, uma mancha no meio da cidade. Temos palavras de ordem, mas o coração está em desordem.

"Hoje eu estou sem chão, estou sem rumo. Não sei o que fazer. Mas, com certeza, essa energia aqui já está nos alentando bastante", disse a esposa de uma vítima, Joyce Oliveira.

Estamos fora de foco, embaçados na nossa dor.

"Eu escutei o nome do meu pai na lista pelo rádio. Ele era maravilhoso, um exemplo de cidadão brasileiro, um exemplo para mim, para qualquer pessoa. É muito bom saber que tem tanta gente que está sensibilizada com tudo isso", lamentou a filha de uma vítima, Renata Oliveira.

Em cima da bandeira, da ordem e progresso, das estrelas, do céu de anil, colocamos nossa esperança. O apoio, temos um nos braços do outro.

A Defesa Civil confirmou que o prédio da TAM Express deve ser demolido ainda nesta semana. Telas de proteção já foram colocadas (...) A TAM informou que 39 vôos que partiriam de Congonhas (...).

As figuras de linguagem utilizadas nesta narrativa acabam por tornar o texto muito mais denso, sem perder a clareza e a objetividade. Trata-se do relato de ações humanas. Poderia ser diferente, mas não foi. "São Paulo ainda tem nuvens escuras no seu céu",
As figuras de linguagem utilizadas nesta narrativa acabam por tornar o texto muito mais denso, sem perder a clareza e a objetividade. Tratase do relato de ações humanas 
metáfora que remete à situação carregada de tristeza, ao clima de melancolia e dor; "As luzes que resistiram se equilibravam (...)" - prosopopéia; somos "uma mancha' no meio da cidade" - metáfora; "Temos palavras de ordem, mas o coração está em desordem" - antítese. Além disso, na frase "Nós estamos distantes, pequenos, ...", Neide Duarte inclui a si mesma, considera-se parte do conjunto dos feridos, diminuídos. Como se deixasse claro: "os problemas dos outros seres são também os meus problemas".

Em 14 de abril de 2008, Neide Duarte fez um convite à reflexão sobre o congestionamento na capital paulista. Na reportagem "Congestionamento monstro", veiculada no Jornal Hoje da mesma emissora, um texto provocativo chama o leitor a pensar e leva-o ao questionamento sobre os grandes problemas urbanos que enfrentamos.

O congestionamento é um monstro com mais de 100 quilômetros de comprimento, que se move lentamente. Ele nos ameaça de dia e de noite, vai nos engolindo aos poucos e emite sons ameaçadores.

Nem parece que somos parte desse monstro, que fomos nós que o criamos e que estamos vivos dentro dele, atrás do reflexo de alguma arquitetura da cidade. "Não vejo os outros motoristas, só vejo os carros. É desumano, completamente", define uma paulistana.

Estamos sempre loucos para sair fora do corpo do monstro e escapar pela traseira. Mas, na maioria das vezes, ainda que a gente consiga ser mais esperto que os outros, mais cedo ou mais tarde acabamos todos no mesmo congestionamento. E temos que ficar ali, parados, carregando uns as mágoas dos outros.

Nós buscamos saídas. No trânsito, temos tempo para tudo: o que faríamos no sofá da sala ou na mesa da cozinha, fazemos no carro. O que seria próprio no espelho do quarto, fazemos no espelho do carro. Mantemos a pose para aguentar, mas o cansaço vai matando a nossa elegância.

Em São Paulo, quando o congestionamento tem "só" uns 90 quilômetros, ficamos felizes. A cada dia a limitação é maior, mas vamos aceitando, resignados com as novas condições. E pensamos que ainda cabemos achamos que os outros é que não estão cabendo.

Crescemos demais, escapamos ao nosso controle. Criamos um monstro, e agora não sabemos como lidar com ele. E nem com os nossos sentimentos. "Fico sufocada, como se eu estivesse perdida. Não tem para onde correr", explica uma motorista.

No meio do caos, onde tanta gente sem rosto parece com o inimigo, é bom estar atento: sempre podemos nos surpreender e dar de cara com um amigo, bem ao nosso lado.

A autora compara metaforicamente o congestionamento a um monstro. "É um monstro com mais de 100 quilômetros de comprimento, que se move lentamente". O congestionamento, algo
Na reportagem "Congestionamento monstro", veiculada no Jornal Hoje um texto provocativo chama o leitor a pensar e leva-o ao questionamento sobre os grandes problemas urbanos 
aparentemente tão impessoal, ganha vida na narrativa de Neide Duarte. Somos "lembrados" pela reportagem que, o que há dentro das máquinas - carros, motos, caminhões, ônibus - são pessoas; que os congestionamentos foram criados por seres humanos e são vivenciados cotidianamente pelos mesmos seres humanos! A jornalista continua, usando o recurso da prosopopéia, ao dizer que o congestionamento "(...) nos ameaça de dia e de noite, vai nos engolindo aos poucos e emite sons ameaçadores". Neste ponto, o áudio da reportagem, veiculada no telejornal, deixa fluir buzinas das mais diversas tonalidades e sons de carros acelerando, o que bem caracterizou os "sons ameaçadores" aos quais Neide Duarte se referiu. Sons que ouvimos diariamente, mas a que fomos nos adaptando. Outra vez, lança mão da prosopopéia ao afirmar que "o cansaço vai matando a nossa elegância".

Finalmente, na reportagem sobre a exposição inédita de parte da obra de Francisco de Goya, Neide Duarte utiliza as figuras de linguagem de tal forma que, a impressão do leitor/telespectador, é que Goya estará pessoalmente em São Paulo. De qualquer forma, sua reportagem, veiculada no Jornal Nacional em 12/03/2007, é convite para interagir com a obra do pintor espanhol, falecido em 1828, na França:

Goya está desembarcando em São Paulo. Traz na bagagem touros, guerras, imagens do inconsciente, provérbios, algumas palavras, dramáticas imagens.

Antes de ir para as paredes, cada uma das 218 gravuras de Goya passa por um olhar multiplicador.

Os "Caprichos" ainda estão pelo chão. Um burro ensina outro burro. Um macaco músico e um burro na platéia.

Com essas críticas à sociedade dos séculos 18 e 19, Goya tratou de esconder a série "Caprichos", com medo da inquisição.

Para não ter problemas com a censura, começou a série dos touros. Gravuras fáceis de vender naquela Espanha das touradas.

Depois dos touros, os provérbios, os disparates. Nelas, Goya se entrega ao mundo das sombras, do inexplicável, do inconsciente.

"É um artista que experimentou uma liberdade de criação enorme. Além disso, quando precisa, ele é um intérprete apurado da realidade que ele estava vendo", diz o curador-geral do Masp, Teixeira Coelho. Goya chega agora em São Paulo, mas o rei espanhol Fernando VII está aqui de velho. Faz parte do acervo do Masp esta pintura de Goya. Foi este mesmo rei quem perseguiu e mandou Goya para o exílio.

Talvez o rei não tenha gostado da imagem dele no retrato. Era o jeito de Goya criticar os poderosos: realçar o que tinham de mais feio.

"Ele era, sem dúvida nenhuma um iluminista, portanto um liberal, portanto um revolucionário para a época e isso é um dos traços mais marcantes e mais fantásticos de Goya", afirma o curador.
Na reportagem sobre a exposição inédita de parte da obra de Francisco de Goya, Neide Duarte utiliza as figuras de linguagem de tal forma que,

a impressão do leitor/ telespectador, é que Goya estará pessoalmente em São Paulo 
A narrativa esclarece, amplia o conhecimento, conta-nos uma história, instiga-nos a saber mais sobre o pintor e a descobrir como a pessoa Goya percebeu, expressou, entendeu o mundo. Neide Duarte foi capaz de representar no texto uma certa ironia, traço do próprio artista espanhol: "Talvez o rei não tenha gostado da imagem dele no retrato". Ora, a própria ironia é uma figura de linguagem e leva o leitor/espectador a manter-se ativo frente à narrativa, interagindo com a reportagem. Neide Duarte também se refere às gravuras e quadros de Goya como ao próprio autor, associando um com o outro, recurso possível por meio da metonímia: "Goya chega agora em São Paulo, mas o rei espanhol Fernando VII está aqui de velho"; "[Goya] traz na bagagem touros, guerras, imagens do inconsciente (...)".

De maneira geral, nos três exemplos aqui citados, Neide Duarte convoca-nos para a reflexão. É, ao mesmo tempo, mediadora e parte integrante; é capaz de sentir as dores e as alegrias do outro e de estabelecer conexões, provocando questionamentos, instigando, causando movimento. Coisas do cotidiano ganham sentimentos, expressões, como se fossem humanos e, em sua narrativa, somos convidados a olhar o mundo sob outros ângulos - a começar pela perspectiva do outro.

\section{Considerações acerca de um jornalismo mais humano}

Num mundo racional e racionalista, em que a técnica, a simplificação e o reducionismo, e a fragmentariedade imperam no fazer jornalístico, apresentam-se cada vez mais nítidos exemplos concretos de que é possível desconstruir essas certezas absolutas e colocar no centro do texto jornalístico o ser humano e sua complexidade. O fazer jornalístico de Neide Duarte ilustra bem essas possibilidades.

Não falamos aqui de "souvenires", decorações e "penduricalhos" que melhorariam a "embalagem" sem preocupar-se com o conteúdo. O que importa é essencialmente este último. Circulam pela imprensa diária muitos textos "bem elaborados", atrativos, recheados de recursos próprios da literatura, mas, onde o ser humano é muitas vezes exposto ao ridículo, vítima de toda ordem de preconceito, numa construção textual que não acrescenta, não constrói, não liberta - muito pelo contrário. Por isso, vale a pena insistir - não basta o domínio da técnica jornalística e da estética em si mesma, lançando mão dos mais diversos instrumentais disponíveis. A verdadeira diferença começa na compreensão de mundo do profissional, de seu real compromisso com os demais humanos e com a convicção de que, mais do que "provar a verdade" com dados e entrevistas que se "encaixam" perfeitamente para demonstrar uma tese, sua tarefa é provocar, problematizar, iluminar, narrar histórias contextualizadas.
Não falamos aqui de "souvenires", decorações e "penduricalhos" que melhorariam a "embalagem" sem preocupar-se com o conteúdo. O que importa é essencialmente este último 
Nunca é demais lembrar que isso não será possível sempre, todas as vezes, em todas as pautas, frente a hegemonia do jornalismo mecanicista que impera. Mas, em quilômetros de duro cimento, encontrar uma fresta de terra boa, onde seja possível plantar uma semente, deixar brotar uma flor, também faz parte da capacidade do jornalista, mediador entre dois mundos.

Assim como Neide Duarte existem muitas outras manifestações de liberdade e ousadia na mídia. Jornalistas que ousam assumir a pauta como um projeto a ser desenvolvido, com consequência e responsabilidade, e transformam assuntos banais, simples pautas do cotidiano em boas histórias para se ler. Eles enxergam as brechas, as frestas, as possibilidades e juntam técnica jornalística, ética profissional e muita criatividade para fazer a diferença.

\section{Referências}

CASTRO, Gustavo; GALENO, Alex (Orgs.). Jornalismo e literatura: a sedução da palavra. São Paulo: Escrituras Editora, 2002.

DINES, Alberto. O papel do jornal: uma releitura. $4^{\text {a }}$. ed. rev. e. atual. São Paulo: Summus, 1986.

DUARTE, Neide. Jornalismo e responsabilidade social: o papel dos jornalistas na construção de um novo mundo. In: www.pautasocial.com.br (Agência de Pautas da Responsabilidade Social), 06 de outubro de 2004. Acesso em 03 de maio de 2007.

DUARTE, Neide. O jornalismo como instrumento de defesa dos direitos da infância e adolescência. Texto apresentado no I Seminário "A criança e o adolescente na mídia de MS”, em Campo Grande-MS, julho de 2003.

MEDINA, Cremilda. A arte de tecer o presente: narrativa e cotidiano. São Paulo: Summus, 2003.

MEDINA, Cremilda. Entrevista: o diálogo possível. São Paulo: Ática, 1995.

MEDINA, Cremilda. O signo da relação: comunicação e pedagogia dos afetos. São Paulo: Paulus, 2006.

TERRA, Ernani; NICOLA NETO, José de. 1001 dúvidas de português. 9a . ed. São Paulo: Saraiva, 1999.

TRAQUINA, Nelson. Teorias do Jornalismo I - Porque as notícias são como são. $2^{\text {a }}$. ed. Florianópolis: Insular, 2005.

VICCHIATTI, Carlos Alberto. Jornalismo: comunicação, literatura e compromisso social. São Paulo: Paulus, 2005.

Recebido em 2 de março de 2009

Aprovado em 2 de maio de 2009 